\title{
Factors of Single Use Plastic Reduction Behavioral Intention
}

\author{
Lee Van ${ }^{1}$, Norhadilah Abdul Hamid ${ }^{1 *}$, Md. Fauzi Ahmad ${ }^{1}$, Ahmad Nur Aizat Ahmad ${ }^{1}$, \\ Rumaizah Ruslan ${ }^{1}$, Puteri Fadzline Muhamad Tamyez ${ }^{2}$ \\ ${ }^{1}$ Universiti Tun Hussein Onn Malaysia, Batu Pahat, Johor, 86400, Malaysia \\ ${ }^{2}$ Universiti Malaysia Pahang, Gambang, Pahang, 26300, Malaysia
}

\begin{abstract}
Malaysia had ranked as eighth over the top 20 countries with mismanaged plastic waste. The largest source of this issue was high consumption of single-use plastic by individuals. It is believed that, residents' social behaviour played a significant role in reducing single-use plastic, which contributed to decreased plastic pollution. Therefore, this study investigates the factors that affect residents' single-use plastic behavioural intention in Malaysia using the Theory of Planned Behaviour (TPB). A Quantitative study using survey questionnaire was employed and the total samples were 341 residents in Batu Pahat Johor. All of the data were analysed using regression analysis through Statistical Packages for the Social Sciences (SPSS) software. The results show a positive relationship between all variables except for environmental awareness and law and regulation. At the same time, the most influential factor affecting residents' single-use plastic reducing behavioural intention was the attitude of residents against lower plastic consumption. Future studies were recommended to be conducted in urban areas which could obtain more desired outcomes. Thus, the findings from this research could provide useful and specific information for policy makers to implement effective strategies for protecting the environmental ecosystem in Malaysia.
\end{abstract}

Keywords:

Single Used Plastic;

Resident;

TPB;

Behavioral Intention.

\section{Article History:}

Received: $\quad 02 \quad$ February 2021

Revised: $\quad 08 \quad$ April 2021

Accepted: $\quad 19 \quad$ April 2021

Published: 01 June 2021

\section{1- Introduction}

In recent years, plastic waste becomes one of the world's hot issue in environmental studies including Malaysia. According to Shaw and Sahni (2014), approximately 280 million tons of plastic is produced globally every year [1]. The main contribution to this data was the high consumption of single-use plastic, which is frequently used by humans. Improper disposal of single-use plastic by Malaysian residents also caused landfills that brought significant environmental problem [2]. For example, each single-use plastic ending up in landfills required light energy and 4001000 years to degrade [3]. Because of these issues, many efforts have been taken by Malaysians such as No Plastic Bag Day (NPBD) programme $[2,4,5]$. Empirical study also has been done to investigate the impact of government policies on reducing single-use plastic $[6,7]$.

Single-use plastic is a type of disposable plastic item only meant for one time usage [8]. Since single-use plastic was designed in such way, most consumers would randomly throw it away, and this led to accumulation of disposable plastic waste. Another example of single-use plastic was plastic packaging such as bottles, cups, containers, straws and others [9]. Not only that, single-use plastic also did not biodegrade and needs a long time to decompose especially the polystyrene foam of plastic products such as food containers. Due to the non-biodegradable of single-use plastics in

*CONTACT: Hadilah@uthm.edu.my

DOI: http://dx.doi.org/10.28991/esj-2021-01275

(C) 2021 by the authors. Licensee ESJ, Italy. This is an open access article under the terms and conditions of the Creative Commons Attribution (CC-BY) license (https://creativecommons.org/licenses/by/4.0/). 
nature, it usually ended up as litter or landfills in the environment which is harmful to the ecosystem. Based on UNEP (2018) it was recorded that among nine billion tons of plastic produced worldwide only $9 \%$ had been recycled and the majority ended up in the ocean, landfills or dumps [10]. Ibrahim and Noordin (2020) also stated the issue of single-use plastic straws has attracted global attention because of nearly 437 million to 8.3 billion of plastic straws discarded on coastlines throughout world [11]. Unfortunately, there existed a trend of excessive use of personal protective equipment that materialised from single-use plastic such as face masks and gloves when the COVID-19 pandemic emerged in 2020 [12].

Therefore, residents may make effort in consuming less single-use plastics by instead using reusable bottles and bags [13]. Changing human habits related to human behaviour from avoiding using single-use plastic needs a long time and more effort. It is becoming more challenging when the use of alternatives to single-use plastic such as eco-plastic products, paper bags, and biodegradable plastic bags was less due to the high price. For instance, Kamaruddin et al. (2016) reported that the impact of Malaysian society awareness toward single-use plastic waste was low [14]. In can be said that there must be other factors that could impact intention of Malaysian residents to reduce the use of single-use plastic. Therefore, this study attempted to investigate the factors affecting the residents' behavioural intention on singleuse plastic in helping Malaysia build a healthy ecosystem in developing a green sustainable environment.

As mentioned before, single-use plastic was non-ecofriendly and brought damage to the nation's ecosystem. In fact, residents' social behaviour played an important role in reducing single-use plastic, which contributed to solve the environmental issue of plastic pollution [15]. From literature, the best model identified that best described on behavioural intention is the Theory of Planned Behaviour (TPB) model. This model was selected because Nguyen et al. (2019) had proven that TPB could effectively predict and explain the residents' social behavioural intention of recycling e-waste in daily life [16]. The changing attitude of residents toward reducing single-use plastic depends on their behavioural intention. On the other hand, the TPB model also included variables that improve public perceptions of residents on reducing single-use plastic and build green environment. Hence, this study adopted the TPB to examine determinants affecting single-use plastic reducing behavioural intention of residents in Parit Raja, Johor, Malaysia. In recent years, Parit Raja had substantial growth in resident population due to the nearby location of a few higher education institutions such as University Tun Hussein Onn (UTHM), Institut Latihan Kementerian Kesihatan Malaysia and Kolej Kemahiran Tinggi Mara Sri Gading. According to the statistics shown in the official website of Majlis Perbandaran Batu Pahat (MPBP), the total population in Parit Raja is 3046 people. The households in Parit Raja were indicated as having distinct behavioural intention of reducing single-use plastic.

From the abovementioned statement, this study was intended to determine the relationship between factors and singleuse plastic reducing behavioural intention among residents and identify the most influential factor affecting such behavioural intention.

\section{2- Current Situations and Practices of Single-use Plastic Reducing in Malaysia}

A study by Jambeck et al. (2015) had ranked Malaysia as 8th among the top 20 of countries in mismanaged plastic waste [17]. It produced 0.94 million tons of mismanaged plastic waste and caused serious plastic pollution such that 0.14 to 0.37 million tons of plastic waste ended up as marine debris washed into the ocean. Kamaruddin, Ling, and Hoe (2020) indicated that single-use plastic products are the main type of pollutants in Long Beach, Perhentian Island, Malaysia [18]. This will lead to physical danger to marine life and in consequence caused the reduced material value in the economy. Indeed, the death of marine wildlife through accidental ingestion of plastic chemical substances brings potential loss to national income and substantially impacts the tourism industry [13]. For example, a pilot whale was found died in June 2018 at a water channel of Southern Thailand and border with Malaysia because it swallowed about $1.36 \mathrm{~kg}$ of plastic bags [19]. Hence, the severity of marine littering by single-use plastic cannot be neglected by Malaysians.

The Ministry of Domestic Trade, Cooperative, and Consumerism (MDTCC) had launched the No Plastic Bag Campaign Day in 2011. The nationwide campaign aimed at reducing the high consumption of single-use plastic bag by imposing a RM0.20 service charge for each plastic bag in hypermarkets, supermarkets and grocery stores every Saturday [5]. This was also supported by Brink et al. (2016); they realised the campaign was coupled with Selangor's consumer education and awareness on curbing usage of single-use plastic bags to preserve the environment [9]. On the other hand, the federal government also via the Ministry of Energy, Science, Technology \& Climate Change implemented 'Malaysia's Roadmap Towards Zero Single-use Plastics 2018-2030' with the expectation that stakeholders would adopt a uniform approach to address single-use plastic in a holistic manner.

Not only that, it had been found that the Malaysian government expenditure in managing solid waste including singleuse plastic items was also very high (about RM950 million) under the Ninth Malaysia Plan (RMK9) because it was a national effort in $40 \%$ reduction of improper plastic waste that previously ended up in landfills and ocean leakage [20]. The government made the effort in reducing plastic waste due to the undeniable critical environmental impact that singleuse plastic brought in threatening future sustainability in Malaysia. 


\section{2-1- Behavioural Intention of Residents toward Single-use Plastic Reducing}

The Theory of Planned Behaviour (TPB) was proposed by Icek Azjen that extended and improved from the theory of reasoned action (TRA) by adding the constructs of perceived behavioural control [21]. The TPB model had been widely used in research investigating psychosocial determinants of social behaviour in human life. In TPB, human behavioural intention was assumed as the primary antecedent of behaviour [22]. According to Ajzen (1991), three factors determine behavioural intention: (i) attitudes toward behaviours (positively/negatively of personal attitude and individual beliefs), (ii) subjective norms (perceived social pressure to engage in a behaviour), (iii) perceived behavioural control (the ability of people's belief to perform the behaviour) [21].

The function of TPB model also provided a theoretical framework for examining influential factors of human social behaviour systematically [23]. For instance, it had been applied to predict behavioural intention toward environmentally sustainable development through the component of TPB [15, 22-25]. To be specific, Nur et al. (2015) found evidence when analysing the factors influencing social behaviour on reducing plastic consumption among students at Universiti Putra Malaysia [26]. These prior studies proved that TPB was obvious to be a powerful framework, which attained high predictability in exploring the elements influencing human social behaviour. Hence, the present study has adopted the TPB model to examine determinants that affected single-use plastic reducing behavioural intention of residents in the town of Parit Raja, Johor, Malaysia. The significance was in eliciting residents' single-use plastic reducing intentions in Malaysia, a country with high rank of mismanaged plastic waste system in global terms.

\section{2-2- Hypotheses}

A study by Manzoor (2017) showed that environmental awareness of residents in Tehsil Mendhar, India remained at low level, so they do not have knowledge and perception of situations such as marine pollution, dumpsite litter, wastage leakage and causes of severe of environmental pollution [27]. In contrast, Kamaruddin and Yusuf (2012) indicated the increased environment awareness of Selangor residents by the 'No Plastic Bag Day' campaign had educated residents on the proper way of waste disposal and curbed the single-use plastic usage [14]. Hence, based on these statements, this study hypothesised that:

\section{H1: Environmental awareness has positive relationship with residents' single-use plastic reducing behavioural intention.}

Some of the prior researches showed a positive relationship between human attitude and behavioural intention on reducing single-use plastic. For example, Kumar (2012) claimed that there was strong significant relationship between consumer attitude and purchase intention on eco-products [15]. Additionally, three studies also found that positive attitude toward the reduced and curbed plastic bags caused shift in human behaviour intentions [26, 28, 29]. Thus, it can be hypothesised that:

H2: Attitude toward single-use plastic reducing has positive relationship with residents' single-use plastic reducing behavioural intention.

It was also assumed that higher social pressure would led to stronger residents' behavioural intention toward reducing plastic consumption. This statement was supported by UNEP (2018), which interpreted social pressure from active public response forced the rapid spread of banning single-use plastic initiatives throughout regions of Bangladesh [10]. Not only that, Godfrey (2019) also proved that social pressure affected individuals involved in minimising the use of single-use plastic and it might be due to persuasion or motivation from family members, friends, neighbours, and colleagues [30]. Through those reviewed cases, this study hypothesised that:

H3: Social pressure has positive relationship with residents' single-use plastic reducing behavioural intention.

Dauvergne (2018) found that human behaviour was changed while binding enforcement policy with a penalty system such as levies, taxes and charges on single-use plastic [31]. In addition, Akenji et al. (2020) had concluded the decrease of plastic bag consumption attained higher degree under strict enforcement of laws and regulations [32]. Another evidence was a case study in Latah County, Idaho showing that the federal legislation (House Bill 372) restricted the residents' abilities to take progressive actions especially lower-income households [33]. After reviewing a few of previous studies, the hypothesis was presented as:

H4: Laws and regulations have positive relationship with residents' single-use plastic reducing behavioural intention.

Several worldwide studies had acknowledged that perceived behavioural control would influence the individuals' single-use plastic reducing behavioural intention directly [15, 26, 34, 35]. For instance, the study by Nur et al. (2015), indicated perceived behavioural control was the most influential factor of changed behaviours of UPM students toward reducing plastic consumption if compared to attitudes and subjective norms [26]. As a result, the next hypothesis was constructed to assume perceived behavioural control of Parit Raja residents could affect their effective proenvironmental actions.

H5: Perceived behavioural control has positive relationship with residents' single-use plastic reducing behavioural intention. 


\section{3- Research Methodology}

This study employed a quantitative research design. The instrument was adopted from previous study. A five-point Likert scale has been used. Expert validation in environmental study has been conducted and also pilot test for instrument reliability. Based on Majlis Perbandaran Batu Pahat (MPBP), the total resident population in Parit Raja was 3046 persons. Therefore, with regard to Krejcie and Morgan, total sample size was 341. Random sampling was used because the total population in Parit Raja was known. A total of 350 responses from the Parit Raja residents were obtained, 315 from paper survey (face-to-face distribution) and 35 from online survey during July to August of 2019. The invalid questionnaires, with repeat answer or having missing responses were eliminated from further analysis. The final effective response rate was $98.57 \%$ representing 345 valid questionnairess; these were processed for data analysis.

\section{3-1- Research Process}

The first step was determining the research problem based on selected research area or issue and aimed at solving it effectively. Next, each research was essential to review the literature with related previous studies. This is because the cited related previous studies could support and prove the reliability of statements written by the researcher. The third step in the research process was deriving the conceptual framework.

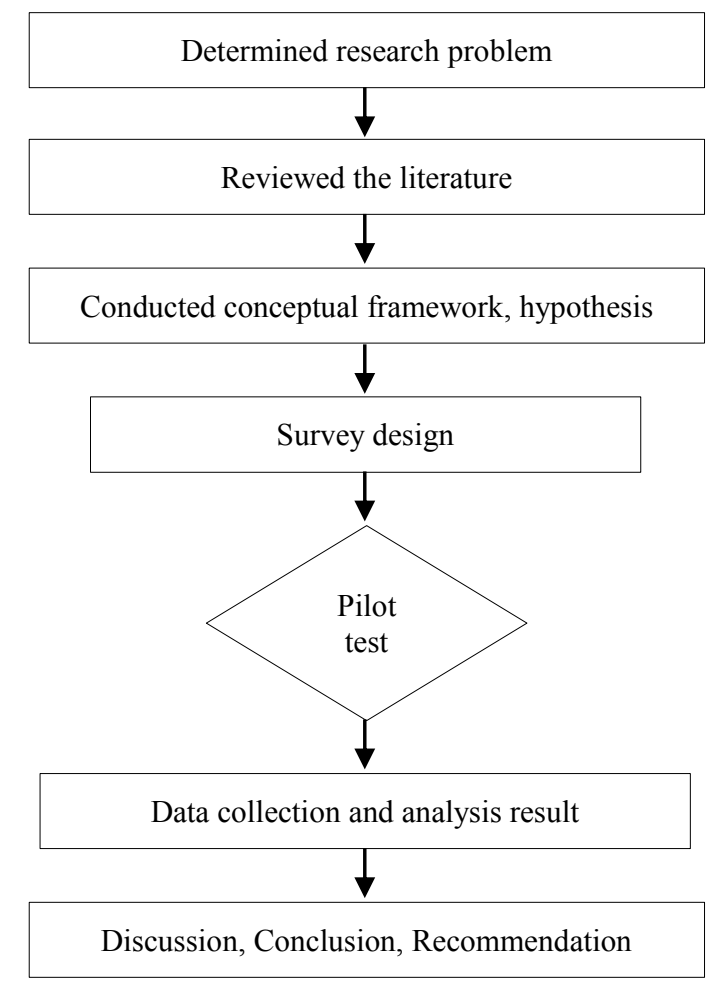

Figure 1. Flow chart of research process.

Through the established framework, hypotheses were derived for testing. In the step of survey design, the researcher must decide on sampling techniques, instrumentation and data analysis method. After that, was constructing questionnaire and carrying out pilot test to ensure the validity of research. The steps were followed by data collection by distribution of questionnaire and then working on data analysis with SPSS software. Lastly, the researcher should interpret and discuss on data analysis and present the conclusions including recommendations for future study.

Questionnaire was the main instrument to conduct the present study. In this study, the questionnaire consisted of three sections, which are demographics of respondents, resident's single-use plastic reducing behavioural intention and five constructs of the determinants. The measurement for dependent variable and independent variables of this study was five-point Likert Scales. The ranking of Likert Scale was $5=$ strongly agree, $4=$ agree, $3=$ neutral, $2=$ disagree, 1 $=$ strongly disagree.

The present study adopted primary data collection method, in which data were collected afresh at the first time. The researcher also used survey questionnaire for collecting primary data. The researcher distributed the questionnaire through two methods namely online survey and paper survey in nearby Parit Raja residents' activities and living areas. 


\section{4- Results}

All data and information collected from the survey questionnaires were analyzed by using Statistical Packages for the Social Sciences (SPSS) Version 22 software.

\section{4-1- Reliability Results}

The result of reliability test is shown in Table 1 and indicates all of the data collected were reliable due to the Cronbach's alpha value greater than 0.7 ; this was considered as acceptable [36].

Table 1. Reliability Statistics.

\begin{tabular}{lcc}
\hline \multicolumn{1}{c}{ Variables } & Cronbach's alpha ( $\boldsymbol{\alpha})$ & N of items \\
\hline Single-use plastic reducing behavioural intention & 0.895 & 5 \\
Environmental Awareness & 0.897 & 5 \\
Attitude towards single-use plastic reducing & 0.911 & 5 \\
Social pressure & 0.880 & 5 \\
Laws and regulations & 0.859 & 5 \\
Perceived behavioural control & 0.896 & 5 \\
\hline \multicolumn{1}{c}{ Overall variables } & $\mathbf{0 . 9 6 7}$ & $\mathbf{3 0}$ \\
\hline
\end{tabular}

\section{4-2- Descriptive Results}

Table 2 shows that overall total mean score for all five independent variables is 3.255 which indicates moderate level. Environmental awareness gave the highest level of mean $=3.471$, followed by attitude, mean $=3.287$, social pressure, mean $=3.256$, laws and regulations, mean $=3.139$ and perceived control behavior, mean $=2.972$.

Table 2. Descriptive result for Independent Variables.

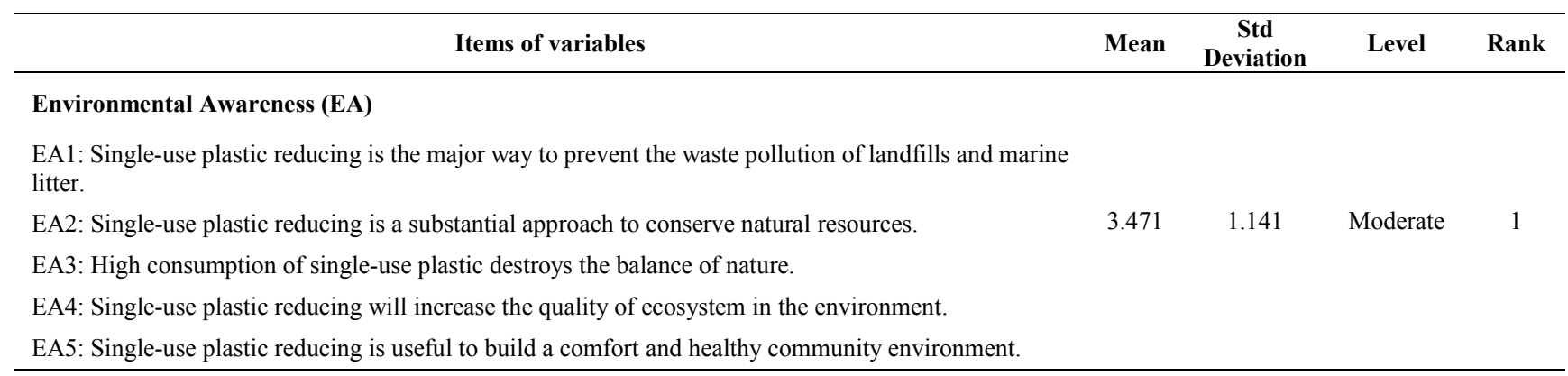

\section{Attitude (A)}

A1: I feel very satisfied that content with reducing the use of single-use plastic.

A2: I believe that the action of reducing single-use plastic will decrease severity of plastic waste pollution.

A3: I feel good while use eco-friendly products to substitute single-use plastic items in daily life.

A4: I am responsible for lower the volume of plastic waste generated.

A5: I am not attracted toward the idea of single-use plastic reducing.

\section{Social Pressure (SP)}

SP1: I will participate in single-use plastic reducing in case with the involvement of relatives, friends and colleagues.

SP2: I may affected by others while they point out of unfriendly behaviours toward environmental.

SP3: The high expectation of friends will engage me in single-use plastic reducing

SP4: Social behaviours of community member are able to change my habit of use single-use plastic.

SP5: Social media influences me to cultivate behaviours of reduce single-use plastic consumption

\section{Law and Regulation (L\&R)}

L\&R1: The levy on single-use plastic charges (RM0.20) will bring impacts of decrease the residents' consumption rate of single-use plastic.

L\&R2: Malaysia' laws and regulations are well equipped with the duties of residents to reduce singleuse plastic.

L\&R3: The restriction of regulations are able to force me lower the usage of single-use plastic.

L\&R4: I will obey towards the laws and regulations relate to single-use plastic reducing in case it's are formulate in Act of Malaysia.

L\&R5: I am not affected by the enforcement of government policy on reducing single-use plastic. 


\section{Perceived Behavioral Control (PBC)}

PBC1: Determine self-constraint over the usage of single-use plastic in a day.

PBC2: I bring my own reusable shopping bag at grocery store.

PBC3: I do not apply for plastic spoons, straws and forks while take-out any food.

PBC5: I choose to purchase environmentally sustainable products regardless of the price in order to decrease the consumption of single-use plastic.

\begin{tabular}{lrr}
\hline Overall & $3.255 \quad 1.126$ & Moderate \\
\hline
\end{tabular}

Next Table 3, shows the total mean score for single-use plastic reducing behavioral intention. Based on the data given in Table 3, the result shows that the mean score for single-use plastic reducing behavioral intention is 3.136 which gives moderate level of intention.

Table 3. Descriptive result for single use plastic reducing behavioral intention (dependent variable).

\begin{tabular}{|c|c|c|c|c|}
\hline Items of variable & Mean & $\begin{array}{c}\text { Std } \\
\text { Deviation }\end{array}$ & Level & Rank \\
\hline \multicolumn{5}{|l|}{ Single-use plastic reducing behavioral intention (RI) } \\
\hline \multicolumn{5}{|c|}{ RI1: I am willing to participate in ‘No Plastic Bag Day’ program conducted by Malaysia’s government. } \\
\hline \multicolumn{5}{|l|}{ RI2: I intend to find the alternatives of instead of using single-use plastic items. } \\
\hline \multicolumn{5}{|l|}{ RI3: I am willing to persuade other individuals to reduce using single-use plastic. } \\
\hline \multicolumn{5}{|l|}{ RI4: I intend to educate my relatives about the way of reducing single-use plastic. } \\
\hline \multicolumn{5}{|l|}{ RI5: I am willing to switch to using plastic-free accessories and tools. } \\
\hline Overall & 3.132 & 1.089 & Moderate & \\
\hline
\end{tabular}

\section{4-3- Regression Result}

In order to identify the impact of independent variables (environmental awareness, attitude, social pressure, law and regulation and perceived behavioral control) toward single-use plastic reducing behavioral intention, regression test was run. The researcher performed regression analysis through SPSS 23.0 and the results are shown in Table 4 and Table 5. Before that, Kolmogorov-Smirnov and Shapiro-Wilk tests were run to examine the assumption of sample data that drawn from a normally distributed population in a study [37]. The result of Kolmogorov-Smirnov test showed p value of 0.000 (below 0.05 ), which indicate that data were not normally distributed.

Table 4. Model Summary.

\begin{tabular}{ccccc}
\hline Model & $\boldsymbol{R}$ & $\boldsymbol{R}$ Square & Adjusted $\boldsymbol{R}$ Square & Std. Error of the Estimate \\
\hline 1 & $0.866^{\mathrm{a}}$ & 0.749 & 0.745 & 0.46526 \\
\hline
\end{tabular}

Table 4 indicated the value of $R^{2}$ is 0.749 that encompassed five of the independent variables (environmental awareness, attitude toward single-use plastic reducing, social pressure, laws and regulations, perceived behavioural control). The coefficients of $R^{2}, 0.749$ represented those independent variables account for $74.9 \%$ of the variance in dependent variable (residents' single-use plastic reducing behavioural intention). There are three estimation levels of $R^{2}$ as $0.75,0.50$ and 0.25 that regarded as correspondent, medium and weak respectively [38]. Overall, the model of regression test of this study was very close to correspondent and pretty good in practice.

Table 5. Coefficients.

\begin{tabular}{|c|c|c|c|c|c|}
\hline \multirow{2}{*}{ Model } & \multicolumn{2}{|c|}{ Unstandardized Coefficient } & \multirow{2}{*}{$\begin{array}{c}\text { Standardized Coefficients } \\
\text { Beta }\end{array}$} & \multirow{2}{*}{$t$} & \multirow{2}{*}{ Sig } \\
\hline & B & Std. Error & & & \\
\hline (Constant) & 0.228 & 0.103 & -- & 2.214 & 0.028 \\
\hline Environmental awareness & 0.034 & 0.046 & 0.036 & 0.751 & 0.453 \\
\hline Attitude & 0.497 & 0.059 & 0.533 & 8.357 & 0.000 \\
\hline Social Pressure & 0.157 & 0.045 & 0.155 & 3.483 & 0.001 \\
\hline Law and Regulation & 0.078 & 0.045 & 0.079 & 1.723 & 0.086 \\
\hline Perceived Behavioral Control & 0.132 & 0.058 & 0.130 & 2.259 & 0.025 \\
\hline
\end{tabular}


In order to determine the significant predictor of residents' single-use plastic reducing behavioural intention this could be represented by the following equation:

$\mathrm{Y}=\mathrm{a}+\mathrm{b}_{1} \mathrm{X}_{1}+\mathrm{b}_{2} \mathrm{X}_{2}+\mathrm{b}_{3} \mathrm{X}_{3}+\mathrm{b}_{4} \mathrm{X}_{4}+\mathrm{b}_{5} \mathrm{X}_{5}$

where, $Y=D V$ (residents' single-use plastic reducing behavioural intention); $a=$ Regression Constant; $b_{1}=$ Unstandardized Coefficients (Beta) of IV1; $b_{2}=$ Unstandardized Coefficients (Beta) of IV2; $b_{3}=$ Unstandardized Coefficients (Beta) of IV3; $b_{4}=$ Unstandardized Coefficients (Beta) of IV4; $b_{5}=$ Unstandardized Coefficients (Beta) of IV5; $\mathrm{X}_{1}=$ IV1 (environment awareness); $\mathrm{X}_{2}=\mathrm{IV} 2$ (attitude towards single-use plastic reducing); $\mathrm{X}_{3}=\mathrm{IV} 3$ (social pressure); $\mathrm{X}_{4}=\mathrm{IV} 4$ (laws and regulations); and $\mathrm{X}_{5}=\mathrm{IV} 5$ (perceived behavioural control).

Based on Table 5, the regression equation for residents' single-use plastic reducing behavioural intention was shown as:

$\mathrm{DV}=0.228+0.034(\mathrm{IV} 1)+0.497(\mathrm{IV} 2)+0.157(\mathrm{IV} 3)+0.078(\mathrm{IV} 4)+0.132(\mathrm{IV} 5)$

Results in Table 5 clearly show that attitude, social pressure and perceived behavioral control give significant effect toward single-use plastic reduction behavioral intention among residents in Parit Raja, Batu Pahat, Johor. Meanwhile, environmental awareness and law and regulations did not significantly affect single-use plastic reduction behavioral intention.

\section{5- Discussion and Recommendations}

This section will discuss the objectives and determine whether they were achieved. Furthermore, we will also explain the contribution and limitations of the study. Consequently, the recommendations were provided to improve existing studies and suggestions were offered for further research.

\section{5-1- Objectives Discussion}

This study had two objectives: to identify the most influential factor affecting residents' single-use plastic reducing behavioural intention and to determine the relationship among them. Based on the statistics of regression test reported earlier, it was obvious that attitude toward single-use plastic reducing was the most influential factor which impact residents' single-use plastic reducing behavioural intention due to its highest beta values among other variables. In other words, residents' attitude toward single-use plastic reduction was very important to arouse their behavioural intention, thus decreasing plastic waste pollution and preserving the healthy environment. In case individuals held active attitude to respond to single-use plastic reducing campaigns, activities and seminars may increase the behavioural intention of residents in reducing plastic consumption. Two previous studies indicated attitudes act as an essential factor influencing the behavioural intention of engaging in reduce, reuse and recycle (3Rs) single-use plastic practice $[16,39]$. Moreover, Ari and Yilmaz (2017) proposed that the positive attitude of human against usage of single-use plastic may assist in switching to using cloth bags [40].

At the same time, the results of regression analysis also showed a positive relationship between all variables except environmental awareness and law and regulation. With regard to environmental awareness, prior studies asserted that even though humans are aware and possessed knowledge of environmental conservation they do not have intention to conduct the action [41]. For instance, the teenagers of Malaysia are concerned about 'green living', but on the contrary the numbers adopting green living still remain low [42]. On the other hand, law and regulations did not significantly affect single-use plastic reduction behavioral intention because the majority of respondents disagree that existing laws and regulations are able to lower usage of single-use plastic.

\section{5-2- Hypotheses Discussion}

From the regression analysis, the authors constructed Table 6 in order to carry out hypotheses testing of significant relationship between factors and resident's single-use plastic reducing behavioural intention. Indeed, the $p$ value (Sig.) was less than alpha value of 0.05 for three out of five hypotheses tested, proving that there existed a positive relationship among variables.

Table 6. Result of hypothesis testing with regression.

\begin{tabular}{|c|c|c|}
\hline Hypotheses & $\begin{array}{l}p \text { value } \\
\text { (Sig.) }\end{array}$ & $\begin{array}{l}\text { Hypothesis accepted/ } \\
\text { Hypothesis rejected }\end{array}$ \\
\hline Environmental awareness has positive relationship with residents' single-use plastic reducing behavioural intention. & 0.453 & Hypothesis rejected \\
\hline $\begin{array}{l}\text { Attitude toward single-use plastic reducing has positive relationship with residents' single-use plastic reducing } \\
\text { behavioural intention. }\end{array}$ & 0.000 & Hypothesis accepted \\
\hline Social pressure has positive relationship with residents' single-use plastic reducing behavioural intention. & 0.001 & Hypothesis accepted \\
\hline Laws and regulations have positive relationship with residents' single-use plastic reducing behavioural intention. & 0.086 & Hypothesis rejected \\
\hline Perceived behavioural control has positive relationship with residents' single-use plastic reducing behavioural intention. & 0.025 & Hypothesis accepted \\
\hline
\end{tabular}




\section{5-3- Contributions of Study}

The result of research demonstrated perspectives, behaviours, attitudes of residents against the single-use plastic reducing may assist in social planning that aimed at building zero pollution of towns. The study also may enhance the understanding of government, policy makers, programmers and other researchers upon residents' behavioural intention and enable implementation of effective campaigns or programs. In a nutshell, this study found that attitude of singleuse plastic reducing has strongest positive relationship with residents' single-use plastic reducing behavioural intention if compared to other factors. Thereby government could put some efforts to achieve desired change in attitude of residents toward single-use plastic reduction. As a result, the issues of plastic waste pollution could be controlled and behavioural shift be adopted by residents that ensure future environmental sustainability.

\section{5-4- Limitations of Study}

The first limitation of the research was time constraints. We had to gather generous data from respondents within one month. Beside that, constraints seen in research design are another limitation in this study. For instance, the questionnaire was designed as closed-ended; some respondents were confused because their desired answers were not in the choices offered and they could not suggest opinions in words. The third restriction in performing the study was accuracy of data. Some respondents might answer the survey questionnaire dishonestly and this cannot be controllable by the researcher.

\section{5-5- Recommendations for Future Researches}

The research could be continued in-depth by studying the residents' single-use plastic reducing behavioural intention in urban areas such as Johor Bahru, Pulau Pinang and Kuala Lumpur. The differences in perceptions and behaviours of rural and urban residents might be huge due to the various factors of educational background, living environment, social mobility and so forth. Future studies may use mix-method of data collection to gather more valuable in-depth information on the research issues. On the other hand, future analysts should consider studying the green purchasing intention of consumers. This is because the increased willingness to purchase eco-friendly products would have significant effect on reducing consumption of single-use plastic.

\section{6- Conclusion}

Today, the severity of plastic pollution is increasing steadily and has become the focus issue on the global stage. The non-biodegradable nature of single-use plastic brought negative impacts and destroyed the natural balance of the environment, causing death of marine organisms. Many previous studies found the critical issue of high consumption of single-use plastic, which cause plastic pollution especially in Malaysia. Hence, this research focused on investigating the determinants of single-use plastic reducing behavioural intention among residents in Parit Raja. The researcher developed a survey questionnaire and interpreted all collected data by using SPSS software. In order to obtain desired result from gathered data, the researcher carried out demographic analysis, descriptive analysis, reliability test, normality test, correlation test and regression test.

Five independent variables encompassing environmental awareness, attitude toward single-use plastic reducing, social pressure, laws and regulations, perceived behavioural control and one dependent variable was residents' singleuse plastic reducing behavioural intention. The two objectives of this research were attained. The result of regression test indicated attitude toward single-use plastic reducing was the most influential factor affecting residents' behavioural intention with the lowest significant level 0.000 and highest beta value 0.533 compared to other variables.

Not only that, this research brought important contribution by providing specific information about factors influencing residents' single-use plastic reducing behavioural intention for readers, government and policy makers. Some limitations such as data collection method, time constraints and behaviours of respondents had restricted the results of this study. Last but not least, recommendations for future study were proposed, which aimed at improving research work in various dimensions; these include researching rural-urban differences in attitude toward single use plastic and mixed-method research design to obtain qualitative data in supporting quantitative findings.

\section{7- Declarations}

\section{7-1-Author Contributions}

All authors contributed to the design and implementation of the research, to the analysis of the results, and to the writing of the manuscript. All authors have read and agreed to the published version of the manuscript.

\section{7-2-Data Availability Statement}

The data presented in this study are available on request from the corresponding author.

\section{7-3-Funding and Acknowledgements}

We extend our appreciation to Universiti Tun Hussein Onn Malaysia for supporting this research. Appreciation also to Manufacturing Technology Management (MTM) focus group, Faculty of Technology Management and Business. 


\section{7-4-Ethical Approval}

Participants gave their written consent to use their anonymous data for statistical purposes. All of them voluntarily collaborated without receiving any financial compensation.

\section{7-5-Conflicts of Interest}

The authors declare that there is no conflict of interests regarding the publication of this manuscript. In addition, the ethical issues, including plagiarism, informed consent, misconduct, data fabrication and/or falsification, double publication and/or submission, and redundancies have been completely observed by the authors.

\section{8- References}

[1] Shaw, Dipak Kumar, and Pranav Sahni. "Plastic to oil." Journal of Mechanical and Civil Engineering (2014): 46-48.

[2] Asmuni, Shahariah, Nur Bashirah Hussin, Jamaliah Mhd. Khalili, and Zahariah Mohd Zain. "Public Participation and Effectiveness of the No Plastic Bag Day Program in Malaysia." Procedia - Social and Behavioral Sciences 168 (January 2015): 328-340. doi:10.1016/j.sbspro.2014.10.238.

[3] Jayaraman, K., Hasnah Haron, Gooi Bee Sung, and Soh Keng Lin. "Consumer Reflections on the Usage of Plastic Bags to Parcel Hot Edible Items: An Empirical Study in Malaysia." Journal of Cleaner Production 19, no. 13 (September 2011): 1527-1535. doi:10.1016/j.jclepro.2011.03.019.

[4] Richards, Cameron, and Irina Safitri Zen. "From Surface to Deep Corporate Social Responsibility." Journal of Global Responsibility 7, no. 2 (September 12, 2016): 275-287. doi:10.1108/jgr-04-2016-0010.

[5] Zen, Irina Safitri, Rahmalan Ahamad, and Wahid Omar. "No Plastic Bag Campaign Day in Malaysia and the Policy Implication." Environment, Development and Sustainability 15, no. 5 (January 25, 2013): 1259-1269. doi:10.1007/s10668-013-9437-1.

[6] Sugii, Takeo. Plastic bag reduction: Policies to reduce environmental impact. Tufts University, (2008).

[7] Xanthos, Dirk, and Tony R. Walker. "International Policies to Reduce Plastic Marine Pollution from Single-Use Plastics (plastic Bags and Microbeads): A Review." Marine Pollution Bulletin 118, no. 1-2 (May 2017): 17-26. doi:10.1016/j.marpolbul.2017.02.048.

[8] Watkins, Emma, Susanna Gionfra, Jean-Pierre Schweitzer, Mia Pantzar, Charlotte Janssens, and Patrick ten Brink. "EPR in the EU Plastics Strategy and the Circular Economy: A focus on plastic packaging." Institute for European Environmental Policy (IEEP) (2017).

[9] Ten Brink, Patrick, Jean-Pierre Schweitzer, Emma Watkins, and Maeve Howe. "Plastics Marine Litter and the Circular Economy." A briefing by IEEP for the MAVA Foundation. More Information (2016).

[10] Giacovelli, Claudia, A. Zamparo, A. Wehrli, and K. Alverson. "Single-use plastics: a roadmap for sustainability." United Nations Environment Programme: Nairobi 90 (2018).

[11] Ibrahim, Nur Raudhah, and Noor Nirwandy Mat Noordin. "Understanding the issue of plastic waste pollution in Malaysia: a case for human security." Journal of Media and Information Warfare 13, no. 1 (2020): 105-140.

[12] Patrício Silva, Ana L., Joana C. Prata, Tony R. Walker, Armando C. Duarte, Wei Ouyang, Damià Barcelò, and Teresa RochaSantos. "Increased Plastic Pollution Due to COVID-19 Pandemic: Challenges and Recommendations." Chemical Engineering Journal 405 (February 2021): 126683. doi:10.1016/j.cej.2020.126683.

[13] Lopez Murcia Martin, Javier. "Social perceptions of single-use plastic consumption of the Balinese population." (2015).

[14] Kamaruddin, Mohamad Anuar, Mohd Suffian Yusoff, Hamidi Abdul Aziz, Mohd Nordin Adlan, N. Qamaruz Zaman, and Noor Zalina Mahmood. "Assessment of municipal solid waste generation, composition and recyclable potential at selected Kelantan dumping sites, Malaysia." Journal of Scientific Research and Development 3, no. 5 (2016): 204-211.

[15] Kumar, Bipul. "Theory of planned behaviour approach to understand the purchasing behaviour for environmentally sustainable products." (2012).

[16] Thi Thu Nguyen, Hong, Rern-Jay Hung, Chun-Hung Lee, and Hang Thi Thu Nguyen. "Determinants of Residents' E-Waste Recycling Behavioral Intention: A Case Study from Vietnam.” Sustainability 11, no. 1 (December 29, 2018): 164. doi:10.3390/su11010164.

[17] Jambeck, J. R., R. Geyer, C. Wilcox, T. R. Siegler, M. Perryman, A. Andrady, R. Narayan, and K. L. Law. "Plastic Waste Inputs from Land into the Ocean." Science 347, no. 6223 (February 12, 2015): 768-771. doi:10.1126/science.1260352.

[18] Kamaruddin, Hanim, Sarah Tan Yen Ling, and Loh Ing Hoe. "Externalities of business entities from plastic pollution at Perhentian island, Malaysia." Opción: Revista de Ciencias Humanas y Sociales 91 (2020): 1380-1404.

[19] Harris, P.T., L. Westerveld, B. Nyberg, T. Maes, M. Macmillan-Lawler, and L.R. Appelquist. "Exposure of Coastal Environments to River-Sourced Plastic Pollution." Science of The Total Environment 769 (May 2021): 145222. doi:10.1016/j.scitotenv.2021.145222. 
[20] Ali, Nor Eeda, H. C. Siong, Kasypi Mokhtar, Nurain Mohd Talmizi, and Alia Abdullah Saleh. "Solid waste management in Shah Alam City residential area." Journal of Sustainability Science and Management 13, no. 1 (2018): 211-227.

[21] Ajzen, Icek. "The Theory of Planned Behavior.” Organizational Behavior and Human Decision Processes 50, no. 2 (December 1991): 179-211. doi:10.1016/0749-5978(91)90020-t.

[22] De Groot, Judith, and Linda Steg. "General Beliefs and the Theory of Planned Behavior: The Role of Environmental Concerns in the TPB.” Journal of Applied Social Psychology 37, no. 8 (August 2007): 1817-1836. doi:10.1111/j.1559-1816.2007.00239.x.

[23] Pakpour, Amir H, Isa Mohammadi Zeidi, Mohammad Mahdi Emamjomeh, Saeed Asefzadeh, and Heidi Pearson. "Household Waste Behaviours Among a Community Sample in Iran: An Application of the Theory of Planned Behaviour." Waste Management 34, no. 6 (June 2014): 980-986. doi:10.1016/j.wasman.2013.10.028.

[24] Minelgaite, Audronè, and Genovaitè Liobikienè. "Waste Problem in European Union and Its Influence on Waste Management Behaviours." Science of The Total Environment 667 (June 2019): 86-93. doi:10.1016/j.scitotenv.2019.02.313.

[25] Tonglet, Michele, Paul S Phillips, and Adam D Read. "Using the Theory of Planned Behaviour to Investigate the Determinants of Recycling Behaviour: a Case Study from Brixworth, UK.” Resources, Conservation and Recycling 41, no. 3 (June 2004): 191-214. doi:10.1016/j.resconrec.2003.11.001.

[26] Hasan, Sharifah Nur Munirah Syed, Rosta Harun, and Lim Kuang Hock. "Application of Theory of Planned Behavior in Measuring the Behavior to Reduce Plastic Consumption among Students at Universiti Putra Malaysia, Malaysia." Procedia Environmental Sciences 30 (2015): 195-200. doi:10.1016/j.proenv.2015.10.035.

[27] Manzoor, Javed. “An Assessment of Environmental Awareness Among the Residents of Tehsil Mendhar, District Poonch J\&K, 185211, India." International Journal of Scientific Research and Management 5, no. 7 (July 10, 2017): 6265-6270. doi:10.18535/ijsrm/v5i7.59.

[28] Risqiani, Renny, and Siti Maemunah. "Building the Attitude of Consumer Concern for Environmentally Friendly Products." Business and Entrepreneurial Review 15, no. 2 (June 18, 2019): 201-212. doi:10.25105/ber.v15i2.4634.

[29] Vimal, K.E.K., K. Mathiyazhagan, Vernika Agarwal, Sunil Luthra, and K. Sivakumar. "Analysis of Barriers That Impede the Elimination of Single-Use Plastic in Developing Economy Context.” Journal of Cleaner Production 272 (November 2020): 122629. doi:10.1016/j.jclepro.2020.122629.

[30] Godfrey, Linda. "Waste Plastic, the Challenge Facing Developing Countries—Ban It, Change It, Collect It?" Recycling 4, no. 1 (January 10, 2019): 3. doi:10.3390/recycling4010003.

[31] Dauvergne, Peter. "The Power of Environmental Norms: Marine Plastic Pollution and the Politics of Microbeads." Environmental Politics 27, no. 4 (March 12, 2018): 579-597. doi:10.1080/09644016.2018.1449090.

[32] Akenji, Lewis, Magnus Bengtsson, Yasuhiko Hotta, Mizuki Kato, and Matthew Hengesbaugh. "Policy Responses to Plastic Pollution in Asia.” Plastic Waste and Recycling (2020): 531-567. doi:10.1016/b978-0-12-817880-5.00021-9.

[33] Gentry, Danielle D. Pass On Plastic: Community Attitudes and Behaviors Towards Single-Use Plastic Bags and the Impact of Local Government Legislation. University of Idaho, (2016).

[34] Chang, Sheng-Hsiung, and Ching-Hsien Chou. "Consumer Intention toward Bringing Your Own Shopping Bags in Taiwan: An Application of Ethics Perspective and Theory of Planned Behavior." Sustainability 10, no. 6 (May 31, 2018 ): 1815. doi:10.3390/su10061815.

[35] Ertz, Myriam, Rong Huang, Myung-Soo Jo, Fahri Karakas, and Emine Sarigöllü. "From single-use to multi-use: Study of consumers' behavior toward consumption of reusable containers." Journal of environmental management 193 (2017): 334-344. doi:10.1016/j.jenvman.2017.01.060.

[36] Sekaran, Umar, \& Bougie, Roger. "Research Method for Business: A skill building approach.” New York: John Wiley \& Sons Inc. (2016).

[37] Rose, Susan, Nigel Spinks, and Ana Isabel Canhoto. Management research: Applying the principles. Routledge, (2014).

[38] Hair Jr, Joseph F., G. Tomas M. Hult, Christian Ringle, and Marko Sarstedt. A primer on partial least squares structural equation modeling (PLS-SEM). Sage Publications, (2016).

[39] Jibril, Jibril Danazimi. "Reduce Reuse Recycle Behavioural Intention Model in Higher Education Institution Accommodation." PhD diss., Universiti Teknologi Malaysia, (2015).

[40] Ar1, Erkan, and Veysel Y1lmaz. "Consumer Attitudes on the Use of Plastic and Cloth Bags." Environment, Development and Sustainability 19, no. 4 (April 11, 2016): 1219-1234. doi:10.1007/s10668-016-9791-x.

[41] Mei, Neo Sau, Choong Weng Wai, and Rahmalan Ahamad. "Environmental Awareness and Behaviour Index for Malaysia." Procedia - Social and Behavioral Sciences 222 (June 2016): 668-675. doi:10.1016/j.sbspro.2016.05.223.

[42] Abd Rahim, Mohd Helmi, Ros Zayanah Johari Ahmad Zukni, Fauziah Ahmad, and Novel Lyndon. "Green Advertising and Environmentally Responsible Consumer Behavior: The Level of Awareness and Perception of Malaysian Youth.” Asian Social Science 8, no. 5 (March 28, 2012): 46-54. doi:10.5539/ass.v8n5p46. 